\title{
Engajamento acadêmico: desafios para a permanência do estudante na Educação Superior
}

\author{
Academic engagement: challenges for student permanence in Higher Education \\ Compromiso académico: desafíos para la permanencia del estudiante \\ en la Educación Superior
}

\author{
MARIA INÊS CÔRTE VITÓRIA* \\ ALAM CASARTELLI** \\ ROSA MARIA RIGO*** \\ PRISCILA TRARBACH COSTA****
}

\begin{abstract}
$\diamond$
RESUMO

$\mathrm{O}$ artigo analisa o engajamento acadêmico e as respectivas implicações pedagógicas. A análise parte do grupo de estudo "Engagement estudantil, calidad de los aprendizajes y abandono en la universidad", do qual fazem parte 11 grupos de pesquisa, desenvolvidos em Redes de Cooperação em seis países distintos. $\mathrm{O}$ vocábulo engagement revela-se portador de uma multiplicidade de significados cuja abrangência e complexidade dificultam as tentativas de estabelecimento de um conceito único capaz de congregar os inúmeros aspectos que o compõem. Identifica-se a existência de diferentes tipos de engagement (pessoal, moral, social, profissional, identitário, acadêmico, relacional) que, por se referirem a diferentes aspectos da vida dos indivíduos, são analisados de maneira isolada pelas diferentes áreas do conhecimento. Reflete-se sobre as instituições de ensino superior, que têm buscado estratégias para favorecer não apenas o acesso, mas também a permanência dos estudantes nos cursos universitários de maneira a reduzir a apatia estudantil em face do mundo acadêmico e minimizar os altos índices de evasão.
\end{abstract}

Palavras-chave: Engajamento acadêmico. Educação Superior. Permanência na Educação Superior.

\begin{abstract}
The article analyzes the academic engagement and its pedagogical implications. The analysis is part of the study group: "Engagement estudantil, calidad de los aprendizajes y abandono en la universidad", is part of 11 research groups, developed in Cooperation Networks in six different countries. The word engagement reveals itself as having a multiplicity of meanings of comprehensiveness and complex difficulty as attempts to establish a unique concept capable of assembling the residues that compose it. We identify the existence of different types of engagement (personal, moral, social, professional, identity, academic, relational) that, because they refer to the diversity of individuals' lives, are analyzed in isolation in different areas of knowledge. We reflect on how institutions of higher education, which have sought strategies to favor not only access, but a permanence of students in university courses in order to reduce student apathy to the academic world and minimize high rates of evasion.
\end{abstract}

Keywords: Academic engagement. Higher Education. Permanence in Higher Education.

\section{RESUMEN}

El artículo analiza el engagement académico y sus implicaciones pedagógicas. Las análisis son parte de una pesquisa del grupo de estudio: "Engagement estudantil, calidad de los aprendizajes y abandono en la universidad", del cual forma parte 11 grupos de investigación, desarrolladas en Red de Cooperación formada por seis países distintos. El vocablo engagement se revela portador de una multiplicidad de significados cuya amplitud y complejidad dificultan los intentos de establecer un concepto único capaz de congregar los innumerables aspectos que lo componen. Identificamos la existencia de diferentes tipos de engagement (personal, moral, social, profesional, identitario, académico, relacional) que, por su vez, son analizados por las distintas áreas del conocimiento. Sobre las instituciones de enseñanza superior, importante decir que han buscado acciones para favorecer no sólo el acceso, sino la permanencia de los estudiantes en los cursos universitarios, para reducir la apatía estudiantil frente al mundo académico y disminuir los altos índices de deserción.

Palabras clave: Engagement académico. Educación Superior. Permanencia en la Educación Superior.

\footnotetext{
* Pontifícia Universidade Católica do Rio Grande do Sul. <https://orcid.org/0000-0001-6450-429X>. E-mail: <mvitoria@pucrs.br>.

** Pontifícia Universidade Católica do Rio Grande do Sul. <https://orcid.org/0000-0002-7550-0769>. E-mail: <alam.casartelli@pucrs.br>.

*** Pontifícia Universidade Católica do Rio Grande do Sul. <https://orcid.org/0000-0001-8266-1969>. E-mail: <rosa.rigo01@gmail.com>.

**** Pontifícia Universidade Católica do Rio Grande do Sul. <https://orcid.org/0000-0002-1925-8621>. E-mail: <priscilatrarbach@gmail.com>.
} 


\section{ENGAJAMENTO ACADÊMICO: QUE HISTÓRIA É ESSA?}

O presente artigo se propõe a analisar o engajamento acadêmico (engagement) e as respectivas implicações pedagógicas na educação superior. Para tanto, parte das reflexões advindas do grupo de estudo "Engagement estudantil, calidad de los aprendizajes y abandono en la universidad", do qual fazem parte 11 grupos de pesquisa, desenvolvidos em Redes de Cooperação em seis países distintos: Espanha, Itália, Portugal, Argentina, México e Chile. Mais recentemente, também é desenvolvido no Brasil, na Pontifícia Universidade Católica do Rio Grande do Sul, por meio do Programa de Pós-Graduação em Educação/Escola de Humanidades. Trata-se de um projeto com dimensão internacional, que dá possibilidades de elaborações solidárias para uma realidade específica em permanente mudança (PUCRS, 2007), investiga numa perspectiva de compartilhamento de dados em diferentes cenários e estabelece aproximações e/ou recorrências nos diversos aspectos analisados no projeto. Tem por objetivo, dentre outras questões, comparar os seus resultados com os demais parceiros de investigação, bem como analisar a situação da universidade, indicando pistas para o engajamento acadêmico em contextos de educação superior.

Nesse sentido, utilizado nos mais diferentes contextos e nas mais diferentes áreas do conhecimento, o vocábulo engagement revela-se, num primeiro momento, portador de uma multiplicidade de significados cuja abrangência e complexidade impossibilitam ou, no mínimo, dificultam as tentativas de estabelecimento de um conceito único capaz de congregar, em uma simples definição, os inúmeros aspectos que o compõem. Dessa forma, em face dessa polissemia que caracteriza a palavra em foco, percebe-se a existência de diferentes tipos de engagement (pessoal, moral, social, profissional, identitário, acadêmico, relacional, etc.) que, por se referirem a diferentes aspectos da vida dos indivíduos, são analisados de maneira isolada pelas diferentes áreas do conhecimento científico.

No entanto, em uma tentativa de se obter uma visão global e integradora, a palavra engagement aparece como uma variável que se preocupa em investigar por quais razões, por quais meios e em quais circunstâncias um indivíduo consegue desenvolver e manter uma linha de condução, um foco, um direcionamento em relação a uma pessoa, a um grupo, a uma atividade ou a um projeto (BRAULT-LABBÉ; DUBÉ, 2009). No que se refere ao campo educacional, em específico, conforme destacam Pirot e De Ketele (2000), desde o final da década de 1980, a variável engagement vem sendo considerada nas pesquisas que visam a identificar os fatores de sucesso e fracasso na universidade, bem como os fatores e indicadores de uma formação universitária de qualidade.

Nessa perspectiva, é importante atentar para o fato de que a palavra engagement encontra suas origens no vocábulo inglês "engage", que agrega múltiplos significados, incluindo o de comprometimento de alguém, seja com sua própria vida, seja com a sua honra, no sentido de encantar e/ou fascinar uma outra pessoa com a intenção de que esta se torne sua aliada (BARKLEY, 2010). Ainda no que se refere à origem da palavra em questão, o Dicionário Oxford destaca que o vocábulo engagement, datado do início do século XVII, possui o sentido geral de "obrigação legal ou moral" (OXFORD, 2017).

Considerando-se essa origem etimológica do vocábulo, cabe, contudo, destacar que a palavra engagement vem sendo empregada neste estudo como "engajamento acadêmico". Este, por sua vez, é definido como um processo que envolve múltiplos aspectos (afetivos, cognitivos e comportamentais) que, quando mobilizados, permitem o envolvimento efetivo dos estudantes com o meio e com as atividades acadêmicas.

Para Barkley (2010, p. 23), o engajamento acadêmico é um processo composto por dois elementos-chave assim definidos: a) a quantidade de tempo e esforço que os estudantes colocam em seus estudos e em outras atividades e que levam a experiências e resultados que constituem seu sucesso; b) as formas através das quais a instituição de ensino aloca recursos e organiza oportunidades de aprendizagem e serviço para induzir os alunos a participar e se beneficiar de tais atividades.

Sendo assim, o engajamento acadêmico se apresenta como um processo dualístico que envolve não apenas o esforço (físico e psicológico) dos estudantes nas suas dimensões afetiva, comportamental e cognitiva, mas, também, engloba as atividades que as instituições de ensino promovem com o intuito de engajar os estudantes nos processos de ensino e aprendizagem. Ainda de acordo com Barkley (2010, p. 23), o engajamento acadêmico é produto da interação sinérgica entre a motivação e a aprendizagem ativa. Para a autora, a motivação seria o elemento desencadeador que permitiria ao estudante engajar-se na vida acadêmica, ao passo que a aprendizagem ativa, através de atividades acadêmicas dinâmicas e envolventes (resolução de problemas, aprendizagem colaborativa, pesquisa), exerceria papel suplementar e garantiria o pleno engajamento acadêmico.

Corroborando com esse entendimento, Trowler (2010) afirma que o engajamento é muito mais do que o simples envolvimento acadêmico e não se reduz apenas à participação, pois, segundo a autora, o processo de engajar-se exige sentimentos (o aspecto afetivo), compreensão/sentido (sense-making ou fazer sentido), 
assim como atividade (o fazer, a prática). Sendo assim, o engajamento acadêmico emerge como uma variável de relevância a ser investigada em contextos de educação superior não apenas porque se debruça sobre aspectos cognitivos e metodológicos, envolvendo o corpo discente e docente e os processos de ensino e aprendizagem, mas porque lança um olhar investigativo sobre as instituições de ensino, focando sua organização institucional, bem como sua gestão.

Ademais, cabe ressaltar que a temática do engajamento acadêmico, apesar de pertinente, tem sido pouco abordada em trabalhos acadêmicos, segundo demonstra estudo sobre o estado de conhecimento com base em dados extraídos do Banco de Dados de Teses e Dissertações do Instituto Brasileiro de Informação em Ciência e Tecnologia - BDTD-IBICT. Em pesquisa realizada nos meses de março e abril de 2017, utilizando o descritor "engajamento", foram encontrados 1.648 registros, sendo que apenas 36 referiam-se ao engajamento acadêmico na educação superior (de forma direta ou indireta). Essa carência de trabalhos abordando a temática em foco não apenas reforça a pertinência de reflexões sobre a questão do engajamento acadêmico como justifica a possibilidade e a necessidade de se desenvolver investigações nesse campo. Isso porque, de acordo com dados divulgados pelo Instituto Nacional de Estudos e Pesquisas Educacionais Anísio Teixeira (Inep), houve, entre 2010 e 2014, um crescimento na taxa de desistência do curso de ingresso por parte dos alunos ${ }^{1}$.

De acordo com o Inep, em 2010, 11,4\% dos alunos abandonaram o curso para o qual foram admitidos, porém, em 2014, esse número chegou a 49\%. Estariam, pois, esses estudantes engajados? Como ocorre esse engajamento acadêmico estudantil? Quais são os atores e aspectos implicados nesse processo? As instituições de educação superior estão levando em conta essas questões? O que as instituições de educação superior vêm fazendo para promover o engajamento acadêmico de seus estudantes? Eis alguns questionamentos que, somados a outras inúmeras questões instigantes e em articulação com os referenciais teóricos (ainda escassos em língua portuguesa), motivam a refletir sobre o engajamento acadêmico em contextos emergentes de educação superior.

Nesse sentido, toma-se por base o entendimento de Kuh (2009) e Martins e Ribeiro (2017) de que o engajamento acadêmico pode ser analisado através de duas perspectivas distintas, porém complementares, sendo a primeira com foco nos estudantes e a segunda com foco nas instituições de ensino. Sendo assim, o

\footnotetext{
${ }^{1}$ Disponível em: <http://www.brasil.gov.br/educacao/2016/10/mecdefende-reformas-para-reduzir-evasao-em-faculdades $>$. Acesso em: 23 de out. de 2017
}

presente trabalho se propõe, na sequência, a analisar cada uma dessas perspectivas, buscando identificar os aspectos que (im)possibilitam o engajamento acadêmico tanto em nível acadêmico (com foco nos estudantes, ligado às aprendizagens) quanto institucional (com foco nas instituições de educação superior, ligado à vida universitária).

\section{O ENGAJAMENTO ACADÊMICO ESTUDANTIL: DILEMAS E POSSIBILIDADES PARA O ENGAGEMENT DOS ESTUDANTES}

Nos debates educacionais contemporâneos, observa-se a recorrência de uma problemática que, de maneira direta ou indireta, refere-se ao engajamento acadêmico dos estudantes, tanto em relação aos processos de ensino e aprendizagem quanto em relação ao aspecto institucional. Isto é, relativos à vinculação, à identificação e ao envolvimento estudantil com as instituições de ensino superior, que têm buscado, de forma incessante, estratégias para garantir não apenas o acesso, mas, sobretudo, a permanência dos estudantes nos cursos universitários. Para que assim possam reduzir a apatia estudantil no que diz respeito ao mundo acadêmico, potencializar a qualidade dos processos educativos, e, em última instância, minimizar os altos índices de evasão.

Nesse sentido, os múltiplos atores envolvidos nos processos educativos vêm estudando estratégias educativas que promovam o estímulo, a motivação e o envolvimento dos estudantes nos processos educacionais. Afinal, todos querem apropriar-se da arte de encantar/ cativar os estudantes de maneira a engajá-los nas atividades acadêmicas, promovendo a sua permanência e estimulando o sentido de pertencimento à instituição. No entanto, conforme destaca Charlot (2009, p. 9), "só se engaja numa atividade quem lhe confere um sentido", ou seja, muito mais do que motivar e envolver os estudantes em atividades educativas e institucionais, o engajamento efetivo envolve "atividade, sentido, prazer", que são "os termos da equação pedagógica a ser resolvida". Assim como Charlot (2009), Pirot e De Ketele (2000), BraultLabbé e Dubé (2009) Trowler (2010) afirmam que o engajamento acadêmico envolve uma série de elementos que vão além dos aspectos motivacionais por parte do estudante e dos estímulos ofertados pelas instituições de ensino. Há consonância entre os teóricos de que o engajamento acadêmico envolve, no mínimo, três dimensões fundamentais, a saber: a) a dimensão afetiva; b) a dimensão cognitiva; e c) a dimensão comportamental.

A dimensão afetiva envolve a motivação, o desejo de aprender, as aspirações e os desejos pessoais dos estudantes, assim como a identificação e a ligação afetiva dos sujeitos com o objeto de estudo e/ou com a instituição 
de ensino. Essa dimensão envolve, pois, os aspectos subjetivos dos estudantes e que são os desencadeadores de toda e qualquer ação, sobretudo no que se refere às ações e aos processos educativos. A dimensão cognitiva, por sua vez, refere-se à mobilização intelectual ou ao trabalho intelectual colocado em prática pelos estudantes nos processos de ensino e aprendizagem. Assim, além do componente afetivo que desencadeia a ação dos sujeitos, o engajamento acadêmico abarca, igualmente, a dimensão cognitiva, visto que "aprender requer uma atividade intelectual", a mobilização de estruturas cognitivas e criativas (CHARLOT, 2009, p. 9). Por fim, porém não dissociada das demais dimensões, existe a dimensão comportamental que se refere aos aspectos e às manifestações observáveis de engajamento dos estudantes, como, por exemplo, assiduidade, participação, entrega de trabalhos e atividades de natureza similar.

Contudo, cabe destacar que, para que haja um engajamento efetivo dos estudantes, essas três dimensões (afetiva, cognitiva e comportamental) devem atuar de forma sinérgica e ser mobilizadas nos sujeitos em mesmo grau de intensidade e relevância, pois a dimensão afetiva, apesar de ser o elemento propulsor da ação, não possibilita o engajamento acadêmico sem a dimensão cognitiva (o trabalho intelectual) e a dimensão comportamental (as ações, as atitudes). Um estudante motivado nem sempre significa um estudante engajado, de fato, se não houver, ao mesmo tempo, um trabalho intelectual consistente traduzido em ações concretas.

Apesar de se observar na literatura a ênfase que é dada a essas três dimensões como elementos imprescindíveis para o engajamento acadêmico, percebe-se que ainda há desafios a serem superados no sentido da promoção de práticas pedagógicas e institucionais pautadas nessa perspectiva. Isso significa que, embora exista uma profunda preocupação com o engajamento acadêmico dos estudantes, as dimensões afetiva, cognitiva e comportamental nem sempre são levadas em consideração na sua integralidade. A ênfase tem sido expressiva nos aspectos didáticos, metodológicos e avaliativos, que, apesar de serem variáveis fundamentais, por si só não favorecem o engajamento do estudante. Por conta dessa ênfase, porém, faz-se necessário refletir sobre e elaborar estratégias que promovam o engajamento acadêmico de tal forma que contemple as três dimensões acima apresentadas, na sua totalidade, uma vez que separados/ fragmentados dificilmente consigam manter o estudante na universidade.

Por isso as instituições de ensino devem estar cientes da complexidade dos sujeitos que acolhem, buscando conhecê-los, identificando suas potencialidades, mapeando suas fragilidades e desenhando os desafios que eles enfrentam para permanecer na instituição como forma de propor percursos pedagógicos capazes de não somente ensinar. Devem também ser capazes de suscitar a curiosidade, o gostar de aprender, a criatividade e o sentimento de pertencimento. Talvez por isso mesmo, valorizar o conhecimento prévio dos sujeitos que compõem o corpo discente de uma instituição seja imprescindível para se pensar e colocar em prática ações educativas que articulem as múltiplas dimensões promotoras do engajamento acadêmico. Para tanto, faz-se fundamental a articulação entre diferentes dimensões de tal forma que se mobilize no estudante o desenvolvimento de conflitos cognitivos que promovam novas aprendizagens, o aprimoramento do senso estético e a aproximação cada vez mais nítida entre o que se estuda e o que se vive.

Cabe lembrar, ainda, que os espaços acadêmicos devem ser pensados para acolher o estudante, pois não faz muito sentido dar demasiada atenção à dimensão cognitiva se o estudante não se encontrar mobilizado afetivamente com o ambiente acadêmico, ou seja, se os espaços acadêmicos the forem totalmente indiferentes e/ ou pouco aconchegantes. Além disso, ao se enfatizar uma determinada dimensão em detrimento das demais, correse o risco de provocar no estudante a apatia, o tédio, a repulsa e a eventual consequente evasão.

Nessa perspectiva, Trowler (2010) atenta, igualmente, para o fato de que na mesma medida em que os estudantes podem engajar-se de maneira positiva, existe o "engajamento negativo" (negative engagement) e o "não engajamento" (non-engagemento), que também podem se manifestar nas diferentes dimensões que compõem o engajamento acadêmico, conforme demonstra a Tabela 1.

Tabela 1. Exemplos de engajamento positivo e negativo

\begin{tabular}{llll}
\hline Dimensões & Engajamento positivo & Não engajamento & Engajamento negativo \\
\hline Cognitiva & $\begin{array}{l}\text { Atende ou excede no que } \\
\text { se refere às atividades e aos } \\
\text { trabalhos solicitados. }\end{array}$ & $\begin{array}{l}\text { Entrega trabalhos solicitados com } \\
\text { atraso ou os realiza de maneira apressada } \\
\text { e muitas vezes não os executa. }\end{array}$ & $\begin{array}{l}\text { Redefine os parâmetros das } \\
\text { atividades e/ou dos trabalhos. }\end{array}$ \\
$\begin{array}{l}\text { Afetiva } \\
\text { Comportamental }\end{array}$ & $\begin{array}{l}\text { Manifesta interesse. } \\
\text { Assiste às aulas, participa com }\end{array}$ & Fanifesta tédio. & Manifesta rejeição. \\
& Fusiasmo. & & $\begin{array}{l}\text { Boicota, impede as atividades/o } \\
\text { trabalho, interrompe as aulas. }\end{array}$ \\
\hline
\end{tabular}

Fonte: Elaborada pelos autores com base em Trowler (2010, p. 6). 
Apesar de se admitir a existência de uma realidade universitária na qual os estudantes nem sempre estão engajados positivamente em todas as dimensões explicitadas na tabela acima, convém salientar, no entanto, que para que o engajamento acadêmico efetivo ocorra é preciso que seja positivo em todas as dimensões (cognitiva, afetiva e comportamental). Não se pode afirmar que um estudante está realmente engajado se, apesar de mostrar-se participativo nas aulas e manifestar interesse pelos saberes discutidos, não realizar as atividades solicitadas e/ou faltar às aulas sem justificativas.

Assim, é importante destacar que, apesar de se perceber a relevância dada ao aspecto cognitivo e ao papel das metodologias e práticas pedagógicas que muitas vezes surgem como propostas inovadoras (e salvadoras!), o engajamento acadêmico, além de envolver dimensões tanto de caráter objetivo (aspectos comportamentais) quanto subjetivo (aspectos afetivos), deve ser percebido como um processo que não depende apenas do estudante. Este envolve os múltiplos atores que atuam no ambiente acadêmico. Assim sendo, levando em conta os inúmeros aspectos que abrangem a discussão do engajamento acadêmico e tendo já apresentado aspectos importantes que envolvem o estudante, na sequência apresenta-se o panorama do engajamento na perspectiva das instituições de educação superior.

\section{O ENGAJAMENTO ACADÊMICO INSTITUCIONAL: REFLEXÕES ACERCA DO PAPEL DAS INSTITUIÇÕES DE EDUCAÇÃO SUPERIOR NA PROMOÇÃO DO ENGAGEMENT EM NÍVEL INSTITUCIONAL}

De acordo com Kuh e $\mathrm{Hu}$ (2001), o engajamento acadêmico, em nível institucional, envolve políticas e práticas que visam a potencializar a qualidade dos serviços prestados pelas instituições de educação superior. Percebe-se, pois, que o engajamento acadêmico não compreende apenas aspectos que dizem respeito aos estudantes, mas, também, aos que se referem às instituições de educação superior. Nessa perspectiva, Wills (1993) define o engajamento como uma variável composta por duas vertentes diferentes, porém indissociáveis, sendo que uma enfoca o estudante e os processos de ensino e aprendizagem, e a outra lança um olhar sobre as instituições de educação superior, ou seja, com um viés mais institucional.

Partindo, então, do pressuposto de que o engajamento acadêmico envolve múltiplos atores, não dependendo apenas da motivação e dos esforços dos estudantes nas atividades acadêmicas, cabe refletir sobre o protagonismo institucional. Isto é, faz-se necessário (e urgente!) pensar a respeito do entendimento que as instituições de educação superior têm sobre a temática, bem como sobre as ações que vêm sendo ou que poderão ser promovidas, em nível institucional, com a finalidade de motivar, envolver e, por consequência, engajar os estudantes.

Barkley (2010) defende a concepção de que o engajamento acadêmico é produto da motivação e da aprendizagem ativa. Para a autora, essas duas variáveis compõem faces de uma mesma moeda, pois só se desenvolvem se houver a indissociabilidade e a interação entre estas. Aliás, é bastante comum, no universo acadêmico, encontrarem-se trabalhos que enfatizam unicamente o aspecto motivacional dos estudantes, permeados por um tom, ainda que às vezes velado, de reprovação ao comprometimento do aluno. Também é possível perceber certa recorrência, entre os docentes, de falas que demonstram desaprovação do comportamento estudantil: os estudantes leem pouco, não se envolvem nas atividades, participam pouco ou não participam das discussões em sala de aula, mostrando-se ausentes (seja física, seja intelectualmente). Busca-se, então, encontrar maneiras de "motivar" os estudantes através de inovações didático-pedagógicas que possam encantar os estudantes, trazê-los para o ambiente acadêmico, fazê-los participar e permanecer nesse espaço. Ademais, a busca por inovações no fazer pedagógico tem afligido grande parte dos docentes que são ou se responsabilizam pela falta de interesse dos estudantes.

Contudo, sabe-se que a motivação por parte do estudante não é a única variável responsável pelo engajamento acadêmico, pois, ainda de acordo com o entendimento de Barkley (2010), a aprendizagem ativa é componente imprescindível. Esta, por seu turno, dáse através de atividades acadêmicas que superam as tradicionais práticas didático-pedagógicas centradas na transmissão de conteúdos e envolvem a aprendizagem centrada na resolução de problemas, a aprendizagem colaborativa e a pesquisa científica na graduação.

Assim, para a promoção do engajamento acadêmico, além de estarem motivados, os estudantes precisam estar envolvidos em atividades que os mobilizem intelectualmente, que façam sentido (sense-making), que envolvam o protagonismo, a interação entre pares, o trabalho colaborativo em redes de cooperação nacional e internacional, a pesquisa e a inovação - elementos cruciais na formação e atuação profissional dos sujeitos na contemporaneidade. No entanto, o que as instituições de educação superior têm realizado, de fato, com relação a estas e a outras questões que envolvem o engajamento acadêmico? Há ou não a preocupação em se promover, além da motivação estudantil, situações e espaços para o desenvolvimento da aprendizagem ativa? Como as instituições têm avaliado o nível de engajamento acadêmico de seus estudantes? 
Ainda refletindo sobre a dimensão institucional do engajamento acadêmico, cabe destacar as contribuições de Martins e Ribeiro (2017), que sublinham a importância de se considerar o engajamento como variável não apenas relevante, mas imprescindível para a avaliação da qualidade da educação superior. Nesse sentido, os autores destacam que "o engajamento é um fator já estudado e avaliado internacionalmente" (MARTINS; RIBEIRO, 2017) e atentam para o fato de que alguns países já possuem instrumentos de avaliação específicos. Estes concebidos com a finalidade de avaliar o grau de engajamento acadêmico dos estudantes universitários. Assim sendo, nos Estados Unidos, esse engajamento é avaliado através do National Survey of Student Engagement (NSSE); na Austrália, através do Australian Survey of Student Engagement (Ausse); e na África do Sul, através do South Africa Survey of Student Engagement (Sasse).

Apesar de cada um desses instrumentos possuírem características próprias e serem aplicados em contextos educacionais distintos, todos foram concebidos com a preocupação de avaliar o nível de engajamento acadêmico com vistas a fornecer às instituições de educação superior, dados que subsidiem a elaboração de políticas e ações institucionais que possibilitem, de fato, o engajamento dos estudantes universitários e favoreçam a sua permanência nos cursos de graduação.

No que concerne ao contexto brasileiro, no entanto, ainda não há instrumentos avaliativos que forneçam indicadores sobre o grau ou nível de engajamento dos estudantes de educação superior. Aliás, o Sistema Nacional de Avaliação da Educação Superior (Sinaes) é composto pela avaliação externa das instituições de ensino superior e pelo Exame Nacional do Desempenho dos Estudantes (Enade). A avaliação externa, apesar de considerar uma série de aspectos de suma relevância, tais como infraestrutura, corpo docente e projeto político pedagógico dos cursos de graduação, não considera o engajamento acadêmico como variável passível de avaliação. O Enade, por sua vez, apesar de centrar-se no estudante, detém-se na dimensão cognitiva do sujeito, ou seja, propõe-se a avaliar apenas os saberes formais construídos (ou não) ao longo do processo formativo universitário.

Essa estrutura avaliativa corrobora, pois, para que se pense o engajamento acadêmico como um problema pertencente unicamente ao aluno que tem seus conhecimentos avaliados através de uma prova (o Enade), ou, pelo contrário, como pertencente à instituição de ensino, mas com demasiada ênfase nos aspectos de infraestrutura, didática e corpo docente. Sabe-se, porém, que essas variáveis, por si só, atuando de forma isolada, não garantem o engajamento dos estudantes. Isso porque uma infraestrutura de qualidade e referência, por exemplo, apesar de desejável e fundamental, não implica, automaticamente, a criação de ambientes de aprendizagem (dimensão cognitiva) nem a identificação dos estudantes com a instituição (dimensão afetiva), elementos fundamentais para o engajamento acadêmico. Uma didática inovadora, pautada na pesquisa e na utilização de novas tecnologias educacionais, por sua vez, também não garante o engajamento acadêmico dos estudantes se a instituição de educação superior não possuir uma infraestrutura adequada que possibilite a criação de espaços e situações de aprendizagem.

As instituições de educação superior devem, portanto, estar atentas às responsabilidades que possuem no processo de engajamento de seus estudantes, observando a concepção de engajamento acadêmico que vem (ou não!) sendo trabalhada em nível institucional. Assim como as dimensões, afetiva, cognitiva e comportamental que o compõem devem ser consideradas e trabalhadas em conjunto na ocasião do planejamento de políticas e ações institucionais.

A esse respeito, Trowler (2010) apresenta algumas estratégias, em nível institucional, para o engajamento acadêmico que, apesar de serem formuladas por teóricos estrangeiros com base em cenários educacionais internacionais, podem ser consideradas nas reflexões que levam em conta a realidade nacional. A primeira delas refere-se ao envolvimento de blended professionals, isto é, profissionais (sobretudo docentes, coordenadores, gestores) que atuam em um espaço fluido entre o ambiente acadêmico e o profissional e que, a partir desse transitam entre os diferentes espaços, auxiliam os estudantes a trilharem seus percursos formativos, considerando ambos os espaços. Aliás, sabe-se que, sobretudo em contexto brasileiro, um dos fatores que impedem ou dificultam o engajamento acadêmico dos estudantes é a falta de articulação entre o mundo acadêmico e o mundo do trabalho, entre a teoria e a prática profissional.

Outra estratégia que pode ser empreendida pelas instituições refere-se à concepção de "planos de engajamento institucional", envolvendo a criação de grupos de trabalho capazes de refletir, identificar e promover iniciativas de engajamento acadêmico. As ações desses grupos de trabalho, no entanto, devem se pautar em alguns princípios fundamentais, que abarcam: 1) a criação e a manutenção de um ambiente intelectual estimulante; 2) a valorização do trabalho acadêmico; 3) o acompanhamento dos diferentes grupos e minorias que constituem o corpo discente; 4) a criação de estratégias que assegurem que as expectativas de trabalho acadêmico sejam claras e passíveis de entendimento e realização pelos estudantes; 5) o fomento de conexões sociais; 6) o reconhecimento dos desafios que os estudantes enfrentam; 7) o fornecimento de estratégias de autogestão discente; 
8) a utilização dos processos avaliativos para refletir sobre a experiência acadêmica do estudante e incentivá-lo a engajar-se; 9) o gerenciamento das experiências de aprendizagem on-line; e 10) o reconhecimento da complexidade do engajamento acadêmico nas políticas e práticas institucionais (KRAUSE, 2005, citado por TROWLER, 2010, p. 44-46).

Ainda pensando em estratégias institucionais para a promoção do engajamento, cabe destacar a importância da criação de um "ambiente solidário e cooperativo entre a comunidade acadêmica", sobretudo no que diz respeito ao relacionamento docente-discente. Nesse sentido, apesar de estarem impregnados de subjetividade, os relacionamentos interpessoais podem ser estimulados através da promoção de uma cultura acadêmica pautada na solidariedade, na empatia, na hospitalidade, no trabalho cooperativo e na criatividade (TROWLER, 2010). Sob essa ótica, é possível perceber, portanto, que, quanto mais os docentes interagem e prestam suporte aos discentes, maiores são, a mobilização por parte destes e o consequente engajamento. Dessa forma, as instituições de educação superior devem levar em consideração que o relacionamento entre professores e estudantes não pode ser meramente formal, pautado apenas na transmissão de conteúdos, nos saberes formais. Um professor de saber notável ao ignorar as dificuldades e potencialidades dos estudantes pode apresentar uma visão equivocada sobre os processos de ensino e aprendizagem e criar situações que, ao invés de promover o engajamento acadêmico, resulte em não engajamento (apatia, desmotivação, evasão) ou engajamento negativo (boicotes às aulas, não realização das atividades).

A partir das discussões conduzidas neste trabalho, sustenta-se, pois, que o engajamento acadêmico em nível institucional é questão de suma relevância a ser considerada na elaboração de políticas e ações institucionais, articulando-se com as variáveis que contemplam os aspectos relacionados à infraestrutura, ao corpo docente e ao projeto político pedagógico dos cursos de graduação. Além de envolver e mobilizar os diferentes atores da comunidade acadêmica. Acredita-se, porém, que as discussões que envolvem o engajamento acadêmico não se esgotam neste trabalho. Espera-se que as reflexões suscitadas possam, em última instância, servir para clarificar o conceito de engajamento acadêmico estudantil e institucional, bem como para problematizar suas implicações para a educação superior brasileira.

\section{À GUISA DE CONCLUSÃo}

Considerando-se o engajamento acadêmico uma variável complexa e passível de investigação na medida em que envolve os múltiplos atores e as interações que se processam no ambiente acadêmico, gerando implicações que afetam toda a comunidade educativa, bem como a qualidade da formação universitária, este artigo espera contribuir no sentido de clarificar o conceito de engajamento acadêmico. Sendo esta uma variável ainda pouco explorada na educação superior no contexto brasileiro, este estudo pode contribuir para a produção e difusão de conhecimento no campo. Na continuidade desse propósito, faz-se importante destacar o papel da reflexão sobre formas de promover o engajamento acadêmico na educação superior. Talvez se possa pensar que o engajamento ou (não) dos estudantes se estabeleça no ambiente acadêmico pela interação do sujeito com o contexto, respondendo ou (não) às intervenções que ocorrem nesses ambientes. Sendo o engajamento acadêmico considerado a variável transversal mais influente nos resultados de aprendizagem e aderência aos estudos (ZEPKE et al., 2011), na condição de pesquisadores, sente-se o desafio de continuar traçando percursos, aprofundando estudos, produzindo dados e análises, com determinação de propósitos e rigor metodológico. Dentre outros aspectos, tem-se como objetivo a promoção de ferramentas de gestão que favoreçam os processos de acesso e permanência dos estudantes na universidade, além da constante (re)construção dos procedimentos de natureza pedagógica. Por isso mesmo, parece mais coerente finalizar este texto apontando reflexões que permitam problematizar aspectos fundantes da educação superior: Qual o papel do ambiente universitário para o engajamento dos estudantes nas dimensões comportamentais, cognitivas e afetivas? $\mathrm{O}$ engajamento comportamental e afetivo promove o engajamento cognitivo? Os ambientes de aprendizagem conseguem manter o engajamento comportamental e o cognitivo no decorrer da graduação? Em busca dessas respostas e da elaboração de mais perguntas, pretende-se dar continuidade aos estudos que reafirmam a importância dessa temática para o debate contemporâneo. Afinal, em meio a tantas incertezas e sentidos de impermanência, o que não muda (felizmente) é que o estudante continua a ser a principal razão da universidade e dos mais árduos e válidos esforços.

\section{REFERÊNCIAS}

ASTIN, Alexander W. (1999). Student involvement: a developmental theory for higher education. Journal of College Student Development, v. 40, n. 5, p. 518-528, set./out. 1999.

BARKLEY, Elizabeth F. Student engagement techniques: a handbook for College Faculty. Jossey-Bass, 2010.

BRAULT-LABBÉ, Anne; DUBÉ, Lise. Mieux comprendre l'engagement psychologique: revue théorique et proposition d'un modèle intégratif. Les Cahiers Internationaux de Psychologie Sociale, n. 81, p. 115-131, 2009. 
CHARLOT, Bernand A escola e o trabalho dos alunos. Anais do XVII Colóquio da Association Francophone Internationale de Recherche Scientifique em Eduction (Afirse), secção portuguesa, 2015. Disponível em: <http://www.afirse.com/ archives/cd2/confer $\%$ C3\%AAncias/Bernard\%20Charlot.pdf $>$. Acesso em: 15 mar. 2017.

ENGAGE. In: Oxford On-Line Dictionary. Disponível em: $<$ https://en.oxforddictionaries.com/>. Acesso em: 14 mar. 2017.

$\mathrm{KUH}$, Georges D.; Hu, S. Learning productivity at research universities. Journal of Higher Education, v. 72, p. 1-28, 2001.

KUH, Georges D. The national survey of student engagement: conceptual and empirical foundations. New Directions for Institutional Research, v. 141, p. 5-20, mar. 2009

MARTINS, Letícia Martins de; RIBEIRO, José Luis Duarte. Engajamento do estudante no ensino superior como indicador de avaliação. Avaliação, Campinas; Sorocaba, SP, v. 22, n. 1, p. 223-247, mar. 2017.

PIROT, Laurence; DE KETELE, Jean-Marie. L'engagement académique de l'étudiant comme facteur de réussite à l'université - étude exploratoire menée dans deux facultés contrastés. Revue des Sciences de l'Éducation, Montréal, v. 26, n. 2, p. 367-394, 2000.

PUCRS., Projeto Pedagógico Institucional da PUCRS, 2007.

TROWLER, Vicki. Student engagement literature review. 2010. Disponível em: <https://www.heacademy.ac.uk/system/ files/studentengagementliteraturereview_1.pdf $>$. Acesso em: 20 mar. 2017.

WILLIS, Deborah. Academic involvement at university. Higher Education, Springer Netherlands, v. 25, n. 2, p. 133-150, mar 1993.

ZEPKE, Nick; LEACH, Linda; BUTLER, Philippa. Noninstitutional influences and student perceptions of success. Studies in Higher Education, v. 36, n. 2, p. 227-242, 2011.

Recebido em 12.07.2017

Aprovado em 20.12.2017

Endereço de correspondência:

Maria Inês Côrte Vitória

Escola de Humanidades

Av. Ipiranga, 6681, Prédio 99A, Portal Tecnopuc, Sala 1519

90619-900 Porto Alegre, RS, Brasil 